\title{
NOTAS SOBRE A EXTENSÃO UNIVERSITÁRIA A PARTIR DE GRAMSCI
}

\author{
NOTAS SOBRE LA EXTENSIÓN UNIVERSITARIA A PARTIR DE GRAMSCI
}

\section{NOTES ON THE UNIVERSITY EXTENSION FROM GRAMSCI}

DOI: http://dx.doi.org/10.9771/gmed.v11i3.29607

Evandro Coggo Cristofoletti

Milena Pavan Serafim

Resumo: O objetivo do artigo é debater possibilidades de se estruturar uma concepção de extensão universitária alicerçada nos pensamentos de Antônio Gramsci. Mobilizou-se, metodologicamente, revisão bibliográfica dos escritos gramscianos e de seus intérpretes a fim de relacionar a temática com conceitos como hegemonia, política, ideologia e intelectuais orgânicos. O argumento desenvolvido partiu de considerações sobre a função social da universidade e dos processos de mercantilização destas, bem como da própria história da extensão universitária no Brasil, para indicar à necessidade de se construí-la enquanto espaço de formação de intelectuais orgânicos junto às classes dominadas.

Palavras-chave: Extensão universitária; intelectual orgânico; aparelho de hegemonia; universidade.

Resumen: El objetivo del artículo es debatir posibilidades de estructurar una concepción de extensión universitaria basada en los pensamientos de Antonio Gramsci. Se movilizó, metodológicamente, revisión bibliográfica de los escritos gramscianos y de sus intérpretes a fin de relacionar la temática con conceptos como hegemonía, política, ideología e intelectuales orgánicos. El argumento desarrollado partió de consideraciones sobre la función social de la universidad y de los procesos de mercantilización de éstas, así como de la propia historia de la extensión universitaria en Brasil, para indicar a la necesidad de construir la extensión como espacio de formación de intelectuales orgánicos junto a las clases dominadas.

Palabras clave: Extensión universitaria; intelectual orgánico; aparato de hegemonía; universidad.

Abstract: The purpose of this article is to discuss possibilities of structuring a conception of university extension based on the thoughts of Antonio Gramsci. Methodologically, a bibliographical review of the Gramscian writings and their interpreters was mobilized in order to relate the theme to concepts such as hegemony, politics, ideology and organic intellectuals. The argument developed was based on considerations about the social function of the university and the concrete processes of their commercialization, as well as the history of university extension in Brazil, to indicate the need to build extension as a space for the formation of organic intellectuals next to the classes dominated.

Keywords: University extension; intellectual property; hegemony apparatus; university.

\section{Introdução}

O objetivo do artigo é indicar, de forma exploratória, possibilidades de se construir uma concepção de extensão universitária alicerçada nos pensamentos de Gramsci. A seguinte pergunta guia nosso debate: é possível elaborar uma concepção de extensão universitária coerente com as reflexões gramscianas? Não pretendemos, dessa forma, lançar mão de um debate puramente conceitual que objetiva definir o que é extensão universitária ou o que ela deveria ser; na verdade, objetiva-se explorar caminhos e possibilidades para se apreender e transformar o objeto em questão, baseados em algumas reflexões mais 
gerais sobre a universidade pública, a história da extensão no Brasil e o ferramental teórico e categorial gramsciano.

Nesse sentido, metodologicamente, realizou-se uma revisão bibliográfica dos escritos de Gramsci e de alguns de seus intérpretes, buscando articular, principalmente, conceitos como hegemonia, ideologia, política e intelectuais orgânicos com alguns debates relativos a universidade pública a extensão universitária no Brasil. Em outras palavras, articulou-se os debates teóricos com algumas questões e problemas que, objetivamente, se fazem presentes nas universidades públicas, especialmente: os processos de mercantilização e privatização do ensino superior; e, além disso, buscou-se tensionar alguns aspectos relativos e específicos à construção da extensão enquanto função universitária no Brasil. O texto partirá para uma discussão acerca das funções sociais da universidade, já incorporando a discussão da mercantilização, para depois se ater as especificidades da extensão, lançando mão de nossa proposta.

\section{Universidade, hegemonia e mercantilização}

De forma geral, pode-se dizer que Gramsci se dedicou à análise da educação durante toda sua trajetória política e intelectual. Reconhece-se, em seu método, a necessidade de apreendê-la enquanto temática relacionada e integrada dialeticamente à totalidade econômico-social (MONASTA, 2010; HOBSBAWM, 2011). À vista disso, argumentaremos à possibilidade de considerar a extensão universitária enquanto uma função que se constitua, baseada no ensino e na pesquisa, enquanto espaço de formação de intelectuais orgânicos junto às classes subalternas1.

Para explicar esta proposta, faz-se necessário apreender a universidade enquanto um aparelho de hegemonia, já que as experiências e atividades de extensão realizadas por estas instituições "são concebidas como partes constituintes daquele aparelho, inseridas, portanto, no conjunto das relações de forças aí implicadas e submetidas às contradições que o caracterizam" (MELO NETO, 2002, p.15). Em outras palavras, estas instituições formam-se e desenvolvem-se a partir de interesses de classe e dos conflitos de classe em processos recheados de mediações. A extensão, nesse sentido, seria apenas uma das formas de se estabelecer relações, mas não a única. Além do mais, a ideia superficialmente difundida de que a universidade seria o lócus de um conhecimento universal e neutro é falaciosa: as relações que estabelecem com seu entorno encontram-se correlacionadas com os conflitos ali existentes, muitas vezes expressos indiretamente, de forma mediada e não determinista, no interior da própria instituição acadêmica (OURIQUES, 2017).

Lembra-se que, para Gramsci, os aparelhos de hegemonia, com forte cunho educativo, formativo e organizativo, são as manifestações materiais, na sociedade civil, dos processos de disputa ideológica e de produção de consensos que contribuem à sustentação e desenvolvimento de determinada infraestrutura econômico-produtiva - processos próprios e característicos das disputas por hegemonia (GRAMSCI, 1999; 2000; 2001; COUTINHO, 1999; MARTINS, 2004; LIGUORI, 2015). Considerandose, nesse sentido, que consenso e coerção de uma classe social sobre outras, a hegemonia é considerada, grosso modo, como o domínio, liderança e direção intelectual e moral exercida pela classe dominante 
sobre a vida social (HOBSBAWM, 2011). Em termos concretos, ela é exercida nos ambientes sociais onde os indivíduos convivem entre si, “através de aparelhos hegemônicos públicos ou privados, como escolas, polícia, parlamento, associações culturais, sindicais, partidos, organizações religiosas, editoras ou jornais" (SILVA, 2016, p.157).

Esta hegemonia é construída constante e deliberadamente pelas classes sociais que buscam produzi-la e disputá-la em processos embebidos de conflitos e contradições e perpassam a sociedade civil e o Estado (HOBSBAWM, 2011; LIGUORI, 2015). Nas palavras de Coutinho (1999, p.97): seguindo os passos de "Marx, Engels, Lênin e Lukács, também em Gramsci a economia determina a política não mediante a imposição mecânica de resultados unívocos, fatais, mas condicionando o âmbito das alternativas que se colocam a ação do sujeito". Nesse sentido, torna-se importante visualizar à possibilidade de luta e construção anti-hegemônica naqueles aparelhos (com limitações, frisa-se). Fica claro, também, que é preciso apreender as especificidades históricas de cada aparelho de hegemonia, pois desempenham funções diferentes na totalidade social, bem como as limitações das lutas anti-hegemônicas no interior destes. Convém mencionar, de forma grosseira, que ideologia em Gramsci significa convencer o outro a agir de forma determinada, ou seja, uma concepção de mundo articulada a uma conduta de ação correspondente (GRAMSCI, 2000; COUTINHO, 1999).

A partir disso, entende-se que Gramsci tenha dado centralidade analítica à política (seja ela a pequena ou a grande política), pois ela estabeleceria o nexo entre a hegemonia, a educação e a produção de conhecimento, na medida em que estes processos se configuram enquanto espaços onde teoria, prática, cultura e política se misturam, e a descoberta e o conhecimento integram-se à ação social (MONASTA, 2010). Além do mais, como vimos, a sociedade civil é uma esfera onde há os aparelhos privados de hegemonia; é uma esfera de mediação entre as relações de produção e o Estado. Disso, decorre que o Estado, em seu sentido ampliado, seria a junção da sociedade política (burocracia estatal executiva, legislativa e judiciária e aparato militar) com a sociedade civil (aparelhos privados de hegemonia, consenso) (GRAMSCI, 2000; COUTINHO, 1999; SILVA, 2016).

Nota-se, então, estreita relação entre a disputa pela hegemonia e a ação do Estado, e as instituições educacionais se configuram enquanto aparatos mediadores nesta relação. As políticas de educação e as universidades públicas, nesse sentido, expressam os conflitos no próprio seio estatal e, no limite, são instrumentos que materializam os valores hegemônicos. Inclui-se aí, claro, a própria extensão universitária.

Conectado a este debate, temos a participação central do intelectual orgânico na construção da hegemonia2. Com Gramsci (2001), pode-se dizer que cada classe social, "nascendo no terreno originário de uma função essencial no mundo da produção econômica, cria para si, ao mesmo tempo, organicamente, uma ou mais camadas de intelectuais que lhe dão homogeneidade e consciência da própria função" (p.15). Dessa forma, o empresário cria para si, por exemplo, o técnico da indústria, o cientista da economia, o gerente, jornalistas, professores, dentre outros, cuja função é organizar e dirigir a vida produtiva, social e política - poder-se ia acrescentar burocratas no Estado, professores e pesquisadores universitários, lideranças políticas diversas, dentre outros; configuram-se, assim, como elos de mediação 
entre grupos sociais e elementos chaves de intervenção ideológica, política e prática nas massas, construindo consensos ao exercício da hegemonia (GRAMSCI, 2000; SILVA, 2016). Além do mais, estes acompanham o desenvolvimento da organização produtiva e estão submetidos a toda sorte de divisões e especializações, culminando, muitas vezes, em um aparente distanciamento em relação à política através de mediações cada vez mais complexas possibilitadas pela criação de instituições sociais (GRAMSCI, 2001). Na visão de Monasta (2010), nas sociedades modernas, estes intelectuais, cada um a seu modo de atuação, podem ser encontrados entre os administradores e técnicos da indústria, professores das mais diversas instituições sociais, nos altos argos da burocracia estatal e na própria atividade de pesquisa e docência acadêmicas.

De fato, as universidades, enquanto aparelhos de hegemonia, "produzem” concretamente os intelectuais orgânicos à classe dominante. De forma mais específica, Marini e Speller (1977, p.3) já haviam pontuado que estas instituições realizam, basicamente, três funções sociais: i. "reprodução das condições ideológicas nas quais a burguesia assenta as bases de sua dominação de classe (...) pela reprodução, na esfera da universidade, da divisão do trabalho, da estrutura de autoridade”, incluindo a separação entre trabalho manual e intelectual; ii. a segunda função, de ordem econômica, "se traduz na transmissão e mesmo criação, através da pesquisa, de técnicas de produção"; iii. e em terceiro, a universidade é um dos campos onde a burguesia estabelece relações e alianças de classe (por exemplo, a questão da possibilidade de promoção social de alguns indivíduos das classes subalternas). É claro que a contra-hegemonia está presente neste processo, como já indicamos.

No Brasil - e na América Latina - podemos adicionar: as universidades participam da própria condição periférica e dependente diante da divisão internacional do trabalho (OURIQUES, 2017; MINTO, 2014). Florestan Fernandes produziu importante bibliografia sobre a questão. Para ele, as universidades estabelecem relação dialética para com a sociedade, e deveriam participar ativamente na superação do subdesenvolvimento e da dependência através de produção de conhecimento novo destinado às necessidades da população e do Estado - desde que radicalmente democrático (FERNANDES, 1991). Contudo, no sentido oposto, uma das principais funções de nossa universidade é fornecer base cognitiva destinada a engordar um "estoque de conhecimento" cuja finalidade é gerar substrato cognitivo à inovação tecnocientífica dos países centrais, contribuindo aos processos de acumulação de capital. Silveira (2016, p.7), debatendo o pensamento de Florestan Fernandes, relata:

Surge a universidade conglomerada como resultado de uma sociedade que se adaptou, estrutural e historicamente, à situação de dependência econômica, social, política, cultural e educacional imposta de fora para dentro, tanto em seu crescimento institucional, quanto na expansão do número de cursos e matrículas (...) Com efeito, toda universidade contribui para o padrão e o ritmo de desenvolvimento tanto da sociedade interna, quanto da sociedade global (...) Em situação de dependência econômica, política e cultural, a sociedade não consegue mobilizar, com eficácia, recursos materiais e humanos visto que o padrão vigente de integração societária à ordem existente se amolda, continuamente, em grau maior ou menor, às formas extremas de desigualdade econômica, sociocultural e política...

Daí, por exemplo, surgem as dificuldades e debilidades materiais de se fazer extensão universitária e comunitária conectada aos problemas reais das classes trabalhadoras. Disso decorre, 
também, segundo Dagnino (2008), nos problemas na plena utilização do conhecimento tecnocientífico na esfera produtiva, derivados de um padrão de desenvolvimento que escanteia a ciência e a tecnologia enquanto motores fundamentais da acumulação - economia baseada fortemente em exportação de commodities e que importa máquinas e equipamentos.

Não somente nas ciências exatas, Fernandes $(1995 ; 2010)$ já alertava ao padrão neocolonial da pesquisa e do ensino, onde se utiliza acriticamente e sem ponderações as perspectivas "importadas" dos centros de conhecimento (EUA e Europa). Ouriques (2017, p.12) retoma esta crítica: "não é preciso muito esforço para perceber que estamos diante de grande disputa intelectual no terreno das ciências sociais [economia, ciência política, sociologia, antropologia, dentre outras]”, que estariam hegemonizadas por perspectivas colonizantes provindas de "Paris e Nova Iorque". Assim, muitos programas de graduação e pós-graduação, amplamente inspirados por aqueles centros, deslocariam as abordagens que, na visão do autor, seriam realmente críticas: "antes da curiosidade intelectual e do compromisso com a superação do subdesenvolvimento (...) o império do efêmero joga nossos estudantes - e especialmente os professores para a necessidade colonial de estar atualizado com a última moda acadêmica” (p.13). Dessa forma, a universidade no Brasil enfrenta problemas que pretendem reduzi-las:

a primeira delas é a redução da universidade a mera formadora de mão de obra, ou seja, sua plena identificação com a posição do país com a divisão internacional do trabalho (...) em poucas palavras, é necessário produzir ensino de qualidade, suficientemente bom para reproduzir a força de trabalho em abundância para as empresas nacionais e principalmente multinacionais. A segunda é a redução da universidade a instrumento de colonialismo mental, cultural e científico (...) Ambas as funções devem ser bem compreendidas: não considero que exista - contra essa universidade que sofremos outra universidade marcada pelo universalismo (...) Portanto, considero insuficiente a crítica que denuncia a universidade operacional sem observar as diferenças da produção de conhecimento entre um país central e outro dependente.

Reforçando nosso argumento: no caminho para pensar em uma extensão universitária mais profícua às classes subalternas, é central considerar a condição dependente de nossa universidade. Com isso, temos um quadro onde se torna fundamental disputar a hegemonia no seio das instituições acadêmicas, mas reconhecendo os próprios limites objetivos e subjetivos desta disputa (pois os determinantes econômico-sociais que produzem esta condição dependente são de ordem societária e econômicas mais amplas).

Quando dizemos disputa por hegemonia, temos em mente também os processos de mercantilização e a privatização pelas quais nossa universidade e nosso ensino superior passam (processo que ganhou fôlego na ditadura militar e se amplia a partir da década de 1990 com o neoliberalismo), configurando-se problemas concretos a serem considerados como entraves à relação entre universidade e trabalhadores (seja no ensino, pesquisa e extensão).

Grosso modo, denominamos de mercantilização da universidade pública e privatização do ensino superior os processos de intensificação da racionalidade mercantil no seio das IES públicas e nas políticas que as afetam, expressas por mudanças objetivas e subjetivas nas políticas internas e externas a estas, bem como o crescimento e oligopolização das faculdades privadas do tipo lucrativas (MINTO, 2014; MARTINS, 2008; LEHER, 2004; MARQUES, 2013; SGUISSARDI, 2015; CORBUCCI et al., 2016; 
LEHER et al., 2017; MANCEBO, 2017). Em outras palavras, pode-se caracterizar este processo como uma aproximação cada vez maior, por parte das universidades públicas, com os interesses e demandas do mercado, seja no âmbito da formação, da pesquisa, da extensão e da gestão (terceirizações de atividades fins e meio, por exemplo), além dos processos de sucatamento e dificuldades econômico-financeiras. No plano do ensino superior como um todo, tem-se a intensificação da fragmentação em organizações especializadas que vendem serviços educacionais, bem como o crescimento e oligopolização do setor lucrativo.

Um bom exemplo da tendência que se desenha à educação superior e à universidade pública esteja contido no relatório divulgado pelo Banco Mundial, chamado de "Um Ajuste Justo: Análise da eficiência e equidade do gasto público no Brasil" (2017). Nele, chega-se a conclusão de que o Estado gasta muito e mal na seguridade social, inclusive na educação superior, produzindo desequilíbrio fiscal. As IES públicas, muito onerosas ao setor público, foram tachadas de ineficientes em termos de custo-benefício se comparadas às IES privadas. A solução seria, para além de estimular maior expansão da rede privadomercantil, fortalecer os mecanismos de captação de recursos externos, inclusive através de cobrança de mensalidades. A análise desconsidera em seus cálculos as diferenças qualitativamente gritantes entre as universidades (pesquisa, ensino e extensão) e grande parte das IES mercantis - tudo para, ao final, garantir o pagamento dos juros da dívida pública.

Dessa forma, qualquer reflexão sobre extensão universitária e comunitária não poderia ignorar tais aspectos. No próximo tópico, passaremos a um debate mais específico desta função acadêmica.

\section{Extensão universitária e a formação de intelectuais orgânicos às classes subalternas}

Compreende-se que, historicamente, a extensão no Brasil se manifestou sob diversas formas e concepções - a depender, basicamente, dos atores envolvidos e de seus objetivos, da forma como se realizou a interação entre universidade e segmento social, e dos condicionantes estruturais e conjunturais dos quais as IES fazem parte (MELO NETO, 2002; PAULA, 2013; SOUZA, 2010). As especificidades históricas da extensão universitária no Brasil mostram sua debilidade enquanto função, bem como um padrão assistemático, assistencialista, voluntarista, fragmentado e pouco conectado ao ensino e a pesquisa. Tendo isso em mente, pode-se dizer que algumas concepções convivem, conflituam-se ou se misturam entre si, como por exemplo: a concepção assistencialista, onde os acadêmicos buscam oferecer assistência à população através de "repasses de conhecimento" ou atuação técnica em problemas pontuais; a prestação de serviços às empresas e governos; a extensão comunitária e suas diversas metodologias e perspectivas ideológicas, teóricas e pedagógicas, que buscam estabelecer relações dialógicas com as comunidades; a concepção de extensão enquanto divulgação científica e formação técnica a um público que não tem acesso ao ensino de graduação e pós-graduação tradicionais, como cursos, palestras e eventos; a extensão enquanto vínculo entre universidade e empresa, especialmente no que se refere à transferência e desenvolvimento de inovações tecnológicas; dentre outros. 
Não retomaremos a história da extensão no Brasil. Hoje, se considerarmos concepções que se pretendem progressistas, encontraremos a produção teórica e prática do Fórum de Pró-Reitores de Extensão das Universidades Públicas Brasileiras, tido como o principal ator extensionista em âmbito nacional - tanto pelo desenvolvimento teórico quanto influência de políticas de extensão à nível nacional e institucional - a partir da redemocratização brasileira ocorrida em 1988 (DINIZ, 2012). Esse ator surgiu no contexto de redemocratização, e vem colocando em pauta temas como cidadania, democratização da universidade, direitos humanos, educação, saúde, trabalho e renda, dentre outros. O Fórum, criado em 1987, vem estimulando debates sobre avaliação, institucionalização e financiamento da extensão.

O Forproex definiu a extensão como "um processo interdisciplinar, educativo, cultural, científico e político que promove a interação transformadora entre Universidade e outros setores da sociedade" (FORPROEX, 2012, p. 15). Em linhas gerais, este conceito apresenta enquanto princípios, embasados por uma matriz freiriana: a ideia de extensão enquanto processo contínuo; a ideia de diálogo e da troca entre os "saberes" acadêmicos e dos grupos sociais; a indissociabilidade e integração entre ensino, pesquisa e extensão; a extensão enquanto produtora de conhecimento e transformadora do ensino e da pesquisa; e a ideia de interdisciplinaridade. Prevalece a ideia de que a extensão seria uma "via de mão dupla" entre o contexto externo e interno, realizando troca de saberes capazes de afetar a pesquisa e o ensino.

Assim, na intenção de chamar a atenção à necessidade de a universidade estabelecer um compromisso para com os problemas sociais da maioria da população através de vínculos processuais e dialógicos, o Fórum acabou por elevar esta função a um status idealizado de "redenção" da universidade enquanto transformadora das outras duas funções e da própria instituição acadêmica, além de um instrumento poderoso de resolução de problemas sociais (MELO NETO, 2002; BOTOMÉ, 1999). Atribuíram, a nosso ver, um peso excessivo e idealizado à extensão, ignorando à necessidade de se pensar, sobretudo, a produção de conhecimento e a formação enquanto dimensões centrais de uma universidade sob a condição de dependência. Em outras palavras, a extensão propagada reveste-se enquanto uma função "salvadora e transformadora", desconsiderando sua fragilidade concreta; e como as principais funções historicamente constituídas são o ensino e a pesquisa, este conceito acaba por desviar a crítica ao centro do problema, qual seja, o próprio padrão de se fazer ciência e ensino, bem como a própria função da universidade como um todo.

Já Melo Neto (2001), assumindo também que o questionamento da relação entre a universidade e a sociedade não pode ser inteiramente mediatizada pela extensão e pela ideia de "via de mão dupla", pontua:

Imagina-se que um ente concreto [a extensão] liga os dois outros constituintes: ensino e pesquisa. Contudo, o ensino e a pesquisa também podem constituir esse ente. Mas será necessário que se saiba o significado de meio que é colocado nessa conceituação. Será o meio um instrumento com o qual se pode chegar a outras conjecturas sobre extensão? Será um instrumento com o qual se domina a própria extensão, o ensino ou a pesquisa? E mais: quais as outras possíveis conjecturas? Será o meio o intermediário para se chegar ao ensino e à pesquisa? Precisa-se desse meio? Extensão é apresentada ainda como "uma forma de corrigir a ausência da universidade na problemática da sociedade". A 
extensão, aqui, se externa como forma. Terá essa forma um conteúdo? Se houver, a questão a ser posta será: E qual é o conteúdo dessa forma? Mas a formulação vai mais além. Nessa compreensão considera-se a universidade como ausente dos problemas da sociedade. É verdade que ela está ausente de vários problemas, mas é também verdade que se faz presente em outros tantos problemas. No campo das Ciências Sociais, por exemplo, por que nos cursos de graduação não se estuda "Brasil" ou "América Latina"? Em tantos cursos de Medicina não se estudam as doenças tropicais. Essas mesmas indagações podem ser feitas em relação à pesquisa. A universidade estará presente, todavia, naquelas temáticas que os setores dominantes definirem para que sejam submetidas ao ensino e à pesquisa (MELO NETO, 2001, p.244-245)

Partindo destas críticas, e adotando uma perspectiva gramsciana, Melo Neto (2002) desenvolveu uma acepção de extensão, considerando-a enquanto trabalho social útil. Nesta formulação, a universidade, através do ensino e da pesquisa, iria à comunidade e construiria, em conjunto a ela, algum tipo de trabalho centrado em problemas concretos. Dessa forma, sendo considerada enquanto um processo de trabalho social, a atuação da universidade junto à comunidade geraria um produto - o próprio conhecimento compartilhado tanto pela universidade quanto pela comunidade ou grupo social. Haveria, assim, uma dimensão educativa nestas comunidades, um trabalho "produtor de conhecimento científico e, ao mesmo tempo, produtor de consciência política para a ampliação da hegemonia dos setores subalternos da sociedade" (MELO NETO, 2002, p.253).

Não temos a pretensão de analisar ou criticar esta acepção. Pretende-se, isto sim, inserir uma dimensão não excludente a esta proposta: a de visualizar a extensão, dentro de uma acepção mais ampla da relação entre universidade e grupos sociais subalternos, como espaço de formação de intelectuais orgânicos juntos a elas, sejam eles os próprios acadêmicos ou - principalmente - através do apoio ao desenvolvimento destes intelectuais nas próprias comunidades. Nessa acepção, a extensão seria um dos espaços de formação, baseada na pesquisa e no ensino, destes intelectuais; mas não seria o único espaço, pois se compreende que a própria pesquisa e ensino - e qualquer arranjo concreto que se faça entre as três funções - possuem condições, mesmo com as limitações destacadas, de se fazer também este movimento. No limite, propõe-se retomar o debate sobre a função do intelectual na política no centro da prática extensionista.

Bom ressaltar que esta concepção posta ao debate não é original: foi percebida por diversos autores latino-americanos e brasileiros que se engajaram, direta ou indiretamente, na reflexão acerca da função social da universidade, bem como da necessidade do envolvimento intelectual com classes subalternas e com os problemas fundamentais da nossa sociedade3. O próprio movimento reformista de Córdoba de 1918 na Argentina, o movimento estudantil brasileiro pré golpe militar e os trabalhos de Paulo Freire (FREIRE, 1983) - cada um a seu modo e no seu contexto histórico - já apregoavam esta necessidade. $\mathrm{O}$ debate trazido aqui apenas visa argumentar à necessidade de se retomar com mais afinco estas questões e trazê-las à tona - apoiado em Gramsci - ao debate extensionista.

Pode-se citar, novamente, os apontamentos de Florestan Fernandes. Próximo a Gramsci no que se refere a questão dos intelectuais, o autor buscou defender, em sua produção teórica e atuação política, a necessidade do engajamento do intelectual em conjunto às classes trabalhadoras a partir de alianças em 
que este e os operários se colocassem em posição de igualdade (FERNANDES, 1995; SILVEIRA, 2006; OLIVEIRA, 2010). Porém, no que se refere ao tipo acadêmico de intelectual, haveriam problemas:

o grande problema do intelectual não está no intelectual e sim na relação da classe trabalhadora com o partido. Se essa for uma relação orgânica e esta conseguir capturar o intelectual para atividades políticas-chave e segundo linhas que sejam firmemente socialistas, a presença do intelectual até que é vantajosa. Agora, se o intelectual ficar desligado da prática política ou se ele tiver uma influência excessiva na retórica do partido, na criação de uma retórica reformista ou até mesmo revolucionária, ele se torna um perigo (FERNANDES, 1995, p. 196).

Dessa forma, viu a necessidade dos acadêmicos e dos cientistas buscarem, no contato com movimentos sociais, um processo de reeducação, em contraposição à formação recebida nas instituições de ensino.

Porém, Semeraro (2006), diante da hegemonia neoliberal e da disseminação das tecnologias de informação e comunicação, traz à tona o debate acerca do declínio dos grandes intelectuais engajados e diretamente conectados com movimentos sociais e políticos; dando lugar, dentre outros, aos intelectuais "desengajados" ou restritos às esferas midiáticas e às novas tecnologias da informação. Nesse sentido, provoca-se:

A figura do intelectual "engajado" entra em declínio e fala-se cada vez menos de intelectuais "orgânicos", das "classes" trabalhadoras, de "militantes" e de educadores populares. Por toda parte, despontam gestores, intelectuais céticos e políticos pragmáticos (...) Sob a forte influência do neoliberalismo na economia e da pós-modernidade na cultura, muitos intelectuais foram gradualmente deslocados do chão da fábrica e dos movimentos de massa para o campo do marketing, da estética e do fantasmagórico cenário da "vídeo-esfera". A crise do intelectual popular acontece não apenas devido à "revolução tecnológica", mas também pela dissolução dos "sujeitos coletivos", pela relativização dos valores públicos, pela derrota do comunismo, pela indistinção entre esquerda e direita e pelo revisionismo imposto às revoluções. Assim, ao longo dessas últimas duas décadas, vimos emergir como onda avassaladora uma crescente categoria de intelectuais que se disseminaram na mídia, na publicidade, no entretenimento, em Organizações Não-Governamentais (ONGs), em serviços administrativos e no controle do sistema (...) A busca da verdade, da justiça, do universal e a visão inspirada na história, na dialética, na totalidade etc. tornaram-se meta-narrativas e produtos autoritários. Em seu lugar, entram o regozijo da des-construção, a elucubração sobre o fragmento, o gosto pela indefinição, a preocupação estilística e ornamental (SEMERARO, 2006, p.382-383)

Convém destacar que o debate acerca da concepção extensionista aqui proposto não visa somente o intelectual acadêmico. Pelo contrário, advoga-se à necessidade de se formar intelectuais orgânicos nas e para as classes subalternas, bem como relações mais orgânicas entre elas e a universidade (MELO NETO, 2002). Nesse sentido, torna-se central examinar as iniciativas de extensão comunitárias existentes para, de forma crítica, inserir esta dimensão nas práticas concretas. O que destacamos, apenas, é um caminho a se pensar as práticas de extensão no interior das universidades, correlacionando-as aos problemas e condicionantes históricos pelas quais a atividade acadêmica esta envolvida e inserindo a discussão da questão do intelectual orgânico enquanto possibilidade de se apreendera extensão. 


\section{Conclusão}

As ideias apresentadas tencionam oferecer reflexões que apoiem, em alguma medida, desenvolvimentos teórico-práticos sobre a extensão universitária e sobre a relação entre a universidade e as classes subalternas. Ao considerar a universidade enquanto aparelho de hegemonia, chegou-se a algumas "conclusões" que se configuram, ao mesmo tempo, como pontos de partida para aprofundamentos necessários. São elas: a necessidade de se resistir aos processos de mercantilização e privatização das universidades públicas e do ensino superior brasileiro, tendo em vista a condição de periférica e dependente de nossa sociedade; a necessidade de se pensar os vínculos entre universidade e classes subalternas enquanto espaços de formação de intelectuais orgânicos junto a elas, o que implica abrir trincheiras de luta contra-hegemônica no ensino, pesquisa (repensando a própria produção científica) e extensão; reconhecer os próprios limites concretos destas lutas nos espaços universitários; pensar em uma postura intelectual diferente por parte dos acadêmicos que, subsumidos por um produtivismo científico alienante, encontram dificuldades à atuação política; e a necessidade de se pensar "pedagogias" e "metodologias" de interação entre a universidade e os grupos subalternos a partir das práticas existentes.

\section{Referências}

BOTOMÉ, Sílvio Paulo. Pesquisa Alienada e Ensino Alienante: o equívoco da extensão universitária. Petrópolis: Vozes, 1996.

CORBUCCI, Paulo Roberto; KUBOTA, Luis Claudio; MEIRA, Ana Paula Barbosa. Reconfiguração estrutural da educação superior privada no Brasil: nova fase da mercantilização do ensino. Texto Para Discussão Ipea, n. 2256, p. 1-42, 2016.

COUTINHO, Carlos Nelson. Gramsci: um estudo sobre seu pensamento político. Rio de Janeiro: Civilização Brasileira, 1999.

DAGNINO, Renato. Por que nossos empresários não inovam? Revista Economia e Tecnologia, v. 13, p. 111 120, abr./jun. 2008.

DINIZ, Flávio Pereira. A extensão universitária como instrumento de política pública. Dissertação (Mestrado) - Universidade Federal de Goiás, Faculdade de Ciências Sociais, 2012.

FERNANDES, Florestan. Em busca do socialismo. Xamã Editora, 1995.

FERNANDES, Florestan. Três teses sobre a universidade (1991). In: OLIVEIRA, Marcos Marques. Florestan Fernandes. Fundação Joaquim Nabuco, 2010.

FORPROEX Fórum Nacional de Pró-Reitores de Extensão das Universidades Públicas Brasileiras. Plano Nacional de Extensão. 1999. Disponível em: <https://www.ufmg.br/proex/renex/documentos/ColecaoExtensao-Universitaria/01-Plano- Nacional-Extensao/Plano-nacional-de-extensao-universitariaeditado.pdf >. Acesso em 22 dez. 2016.

FORPROEX. Fórum Nacional de Pró-Reitores de Extensão das Universidades Públicas Brasileiras. Documento Final do I Encontro de Pró-Reitores de Extensão das Universidades Públicas Brasileiras. UNB, Brasília, 1987. In: NOGUEIRA, Maria das Dores Pimentel (Org.). Extensão Universitária: diretrizes conceituais e políticas. Documentos básicos do Fórum de Pró-reitores de Extensão das Universidades Públicas Brasileiras. Belo Horizonte: PROEX/UFMG; Fórum, 2000.

FORPROEX. Política Nacional de Extensão Universitária. 2012. Disponível em: <https://www.ufmg.br/proex/renex/documentos/2012-07-13-Politica-Nacional-de Extensao.pdf>. Acesso em 22 dez. 2016. 
FREIRE, Paulo. Extensão ou comunicação. Rio de Janeiro: Paz e Terra, 1983.

GRAMSCI, Antonio. Cadernos do cárcere, vol. 1. Edição e tradução de Carlos Nelson Coutinho; coedição de Luíz Sérgio Henriques e Marco Aurélio Nogueira. Rio de Janeiro: Civilização Brasileira, 1999.

GRAMSCI, Antonio. Cadernos do cárcere, vol. 2. Edição e tradução de Carlos Nelson Coutinho; coedição de Luíz Sérgio Henriques e Marco Aurélio Nogueira. Rio de Janeiro: Civilização Brasileira, 2001.

GRAMSCI, Antonio. Cadernos do cárcere, vol. 3. Edição e tradução de Carlos Nelson Coutinho; coedição de Luíz Sérgio Henriques e Marco Aurélio Nogueira. Rio de Janeiro: Civilização Brasileira, 2000.

HOBSBAWM, Eric. Como mudar o mundo: Marx e o marxismo. São Paulo: Companhia das Letras, 2011.

LEHER, Roberto; VITTOÓRIA, Paolo; MOTTTA, Vânia Cardoso. Educação e mercantilização em meio à tormenta político-econômica do Brasil. Germinal: Marxismo e Educação em Debate, v. 9, n. 1, p. 14-24, 2017.

LEHER, Roberto. Para silenciar os campi. Educação e Sociedade, v. 25, n. 88, p. 867-891, 2004.

LIGUORI, Guido. Gramsci's pathways. Tradução de David Broder. Boston: Brill, 2015.

MANCEBO, Deise. Crise Político-Econômica no Brasil: Breve análise da educação superior. Educação \& Sociedade, v. 38, n. 141, p. 875-892, 2017.

MARINI, Ruy Mauro; SPELLER, Paulo. A universidade brasileira. Tradução de Fernando Correa Prado, 1977. Disponível em: <http://www.marini-escritos.unam.mx/pdf/053_universidade_brasileira.pdf>. Acesso em: 13 de jun. 2018.

MARQUES, Waldemar. Expansão e oligopolização da educação superior no Brasil. Avaliação, v. 18, n. 1, p. 69-83, 2013.

MARTINS, André Luiz de Miranda. A Marcha do “Capitalismo Universitário” no Brasil nos anos 1990. Avaliação, v. 13, n. 3, p. 733-743, 2008.

MARTINS, Marcos Francisco. O valor pedagógico e ético-político do conhecimento para a "filosofia da transformação" de Gramsci e sua relação com o marxismo originário. 2004. 312f. Tese (doutorado) Doutorado em Educação, Faculdade de Educação, Universidade Estadual de Campinas, Campinas, 2004.

MELO NETO, José Francisco. Extensão Universitária: uma análise crítica. João Pessoa: Editora Universitária João Pessoa, 2002.

MINTO, Lalo Watanabe. A educação da miséria: particularidade capitalista e educação super or. São Paulo: Outras Palavras, 2014. 400p.

MONASTA, Attilio. Antonio Gramsci. Recife: Editora Massangana, 2010.

OLIVEIRA, Marcos Marques. Florestan Fernandes. Fundação Joaquim Nabuco, 2010.

OURIQUES, Nildo. O colapso do figurino francês: crítica às ciências sociais no Brasil. Florianópolis: Editora Insular, 2017, 206p.

PAULA, João Antônio de. A extensão universitária: história, conceito e propostas. Interfaces - Revista de Extensão, n. 1, p. 05-23, jul./nov. 2013.

SEMERARO, Giovanni. Intelectuais “orgânicos” em tempos de pós-modernidade. Caderno Cedes, v.26, n.70, p.373-391, 2006.

SGUISSARDI, Valdemar. Educação Superior no Brasil: democratização ou massificação mercantil. Educação e Sociedade, v. 36, n. 133, p. 867-889, 2015.

SILVA, Deise Rosálio. Hegemonia e educação: proposta gramsciana de superação da subalternidade. 2016. 435f. Tese (doutorado) - Doutorado em Educação, Faculdade de Educação, Universidade de São Paulo, São Paulo, 2016.

SILVEIRA, Zuleide. A universidade brasileira e o papel do intelectual em Florestan Fernandes. In: $6^{\circ}$ Colóquio Internacional Marx e Engels, 2009. 
SIMINONATTO, Ivete. Classes subalternas, lutas de classe e hegemonia: uma abordagem gramsciana. Revista Katálysis, v. 12, n. 1, p.41-49, 2009.

SOUZA, Ana Luíza Lima. A História da Extensão Universitária. Campinas: Editora Alínea, 2010.

${ }^{1}$ Não aprofundaremos a noção de classes subalternas neste artigo, mas esclarece-se que a utilizamos na acepção Gramsciana - ver Simionatto (2009).

2 Sabe-se que Gramsci (2001) divide em dois os tipos de intelectuais: os tradicionais e os orgânicos. Abordamos aqui unicamente os orgânicos.

3 Como Darcy Ribeiro, por exemplo, em sua "A Universidade Necessária” (DARCY RIBEIRO, 1975). Outro exemplo fecundo é Paulo Freire, inspirador de muitas práticas e concepções extensionistas baseadas numa práxis dialógica e conectada às classes populares.

Recebido em: 15.02.2019

Publicado em: 20.04.2020 